\title{
Maturation of Energy Metabolism in the Lamb: Changes in Myosin ATPase and Creatine Kinase Activities
}

\author{
JOANNE S. INGWALL, ${ }^{(46)}$ MARTHA F. KRAMER, DAVID WOODMAN, \\ AND WILLIAM F. FRIEDMAN \\ Departments of Medicine, Peter Bent Brigham Hospital and Harvard Medical School, Boston, MA; Department of \\ Medicine, University of California, San Diego, La Jolla, CA; and Department of Pediatrics, University of California, \\ Los Angeles School of Medicine, Los Angeles, California, USA
}

\section{Summary}

Studies have been carried out to assess maturation of myofibrillar and mitochondrial proteins in fetal (113 to 140 days gestation), neonatal (30 min to 21 days postpartum), and adult sheep hearts. $\mathrm{Ca}^{++}$-activated myosin ATPase activity was $\sim 20 \%$ lower in fetal than in adult left ventricular myocardium $(1.13 \pm 0.06, n=$ 12 , versus $1.36 \pm 0.07, n=9, \mu$ moles $P_{1}$ per $g$ protein per sec; $P$ $<0.025$ ). In fetal and neonatal hearts (but not in adult hearts), myosin ATPase activity was slightly higher $(\sim 14 \% ; P<0.001)$ in right ventricular tissue than in left ventricular tissue. In contrast to these small changes in myosin ATPase activity, large changes indicative of maturation of energy metabolism occurred in the creatine kinase system: between 115 days gestation and 21 days postpartum, total creating kinase activity increased nearly 8-fold (0.2 to $1.6 \mathrm{IU} / \mathrm{mg}$ cardiac mass), the MM-creatine kinase isozyme increased 7 -fold $(0.2$ to $1.5 \mathrm{IU} / \mathrm{mg}$ wet weight), and mitochondrial creatine kinase increased more than 25 -fold $(<0.01$ to $0.27 \mathrm{IU} /$ mg wet weight). The total creatine pool, but not the ATP pool, increased (from $\sim 6$ to $\sim 15$ nmoles/g tissue). Neither the concentration nor isozyme distribution of lactate dehydrogenase, a glycolytic enzyme, changed during this 7-wk period of development.

\section{Speculation}

We speculate that changes in biochemical composition of energy-utilizing and -producing proteins, coupled with alterations in the structure and cellular distribution of mitochondria and myofibrils, contribute to the changes in mechanical performance characteristic of the maturing heart.

The intrinsic physiologic properties of the normally developing heart of the fetal and newborn lamb have been studied by isolated cardiac muscle techniques $(10,29,37)$, isolated whole heart methods (33), and chronic fetal instrumentation methodology (23, $25,34)$. These studies have helped to define the limits imposed on fetal and neonatal cardiocirculatory adaptation by the mechanics of contraction and the changes in the structure of fetal and newborn myocardium compared to the adult. In general, with advancing age, the mechanical properties of the heart gradually change to resemble those of the adult.

The current studies were undertaken to test the hypothesis that age-related differences in the myofibrillar proteins (ATP-utilizing proteins) or in the proteins important in regulating energy metabolism in the heart (ATP- and creatine phosphate-producing proteins) constitute a biochemical basis for the differences in mechanical performance of the maturing heart. Accordingly, left and right ventricular tissue from late fetal (113 to 140 days gestation), newborn ( $30 \mathrm{~min}$ to 21 days postpartum), and adult sheep hearts were analyzed for myosin ATPase activity and creatine kinase and lactate dehydrogenase isozyme compositions. The results suggest that an age dependency exists in the enzymes important in regulating energy production and utilization.

\section{MATERIALS AND METHODS}

Myocardial tissue was obtained after rapid cardiectomy from 17 fetal sheep ranging in age from 113 to 140 days gestation, 22 newborn lambs ranging in age from $30 \mathrm{~min}$ to 21 days, and 13 adult (mother) sheep.

\section{ENZYME ANALYSES}

Myosin. Myosin (ATPase, EC 3.6.1.3) was isolated from 10 to $20 \mathrm{~g}$ tissue using the method of Katz (21). In all cases, the yield was $\sim 8 \mathrm{mg} / \mathrm{g}$ tissue. Calcium-activated myosin ATPase activity was assayed at $25^{\circ} \mathrm{C}$ in $0.1 \mathrm{M}$ Tris $(\mathrm{pH} 8)$ containing $0.6 \mathrm{M} \mathrm{KCl}$, $10 \mathrm{mM}$ calcium, and $3.1 \mathrm{mM} \mathrm{MgATP}$. The reaction was stopped by adding an aliquot of $70 \%$ perchloric acid. The liberated inorganic phosphate was measured using the Fiske-Subbarrow method (9). Myosin ATPase activity was calculated as moles of inorganic phosphate produced per $g$ protein per sec. The purity of the myosin preparations was assessed using sodium dodecyl sulfatepolyacrylamide gel electrophoresis ( $5 \%$ cross-linked) as previously described (15).

Separate tissue samples were used for analyses of creatine kinase and lactic dehydrogenase activities. Samples were homogenized in $0.1 \mathrm{M}$ potassium phosphate buffer $(\mathrm{pH} 7.4)$ with $1 \mathrm{mM}$ EDTA and $1 \mathrm{mM} \beta$-mercaptoethanol, and allowed to incubate for $1 \mathrm{hr}$ to release mitochondrial isozyme as described by Jacobus and Lehninger (18). Creatine kinase activity (ATP; creatine $N$-phosphotransferase, EC 2.7.3.2) was measured using the coupled enzyme reaction scheme of Rosalki (35). Separation of creatine kinase isozymes was accomplished using cellulose acetate strip electrophoresis as described by Hall and DeLuca (13). Strips were scanned on a Turner fluorometer and areas of the peaks corresponding to each of the isozymes was calculated using a HewlettPackard digitizer.

Lactate Dehydrogenase. Lactate dehydrogenase activity (EC 1.1.1.27) was measured in the direction of lactate production using the method of Bernstein and Everse (3). Activity in the presence of high and low pyruvate was measured to assess relative changes in the composition of aerobic and anaerobic isozymes. Activity was expressed as (milli) IU $/ \mathrm{mg}$ ventricular mass. Aliquots of these homogenates were taken for measurements of protein content using the method of Lowry et al. (28) and for total creatine concentration using the fluorometric assay of Kammermeier (20).

To determine dry weight, 50 to $100 \mathrm{mg}$ pieces of ventricular myocardium were dried at $60^{\circ} \mathrm{C}$ to constant weight. DNA (expressed as $\mu \mathrm{g} / \mathrm{mg}$ fresh tissue weight) was extracted from 50 to $100 \mathrm{mg}$ pieces according to the method of Hinegardner (14). 
Table 1. Properties of fetal, neonatal, and adult sheep hearts

\begin{tabular}{|c|c|c|c|c|c|c|}
\hline \multirow{2}{*}{$\begin{array}{l}\text { Property } \\
\text { Heart wt }(\mathrm{g})\end{array}$} & \multicolumn{2}{|c|}{$\begin{array}{c}\text { Fetal } \\
\text { (113-140 days) }\end{array}$} & \multicolumn{2}{|c|}{$\begin{array}{l}\text { Neonatal } \\
\text { (30 min-21 days) }\end{array}$} & \multicolumn{2}{|l|}{ Adult } \\
\hline & $13.3 \pm 1.1^{1}$ & (12) & & & $237 \pm 18$ & (3) \\
\hline \multicolumn{7}{|c|}{ Protein/wet wt (g/g) } \\
\hline LV & $0.104 \pm 0.067$ & (3) & $0.123 \pm 0.003$ & $(12)$ & $0.109 \pm 0.01$ & (4) \\
\hline RV & $0.096 \pm 0.013$ & (3) & $0.125 \pm 0.005$ & (12) & $0.122 \pm 0.005$ & (4) \\
\hline \multicolumn{7}{|c|}{ Dry weight/wet wt $(\mathrm{g} / \mathrm{g})^{2}$} \\
\hline LV & $0.181 \pm 0.008$ & (7) & $0.221 \pm 0.004$ & (22) & $0.226 \pm 0.007$ & (12) \\
\hline RV & $0.181 \pm 0.010$ & (2) & $0.208 \pm 0.012$ & $(12)$ & $0.227 \pm 0.009$ & (8) \\
\hline \multicolumn{7}{|c|}{ DNA/wet wt $(\mu \mathrm{g} / \mathrm{mg})^{3}$} \\
\hline LV & $3.8 \pm 0.4$ & (6) & $3.2 \pm 0.1$ & $(20)$ & $1.4 \pm 0.1$ & (9) \\
\hline RV & $5.2 \pm 1.0$ & (3) & 3.4. \pm 0.3 & $(8)$ & $1.3 \pm 0.2$ & (5) \\
\hline
\end{tabular}

\footnotetext{
${ }^{1}$ Mean \pm S.E. for left (LV) and right (RV) ventricles.

${ }^{2} P<0.001$ fetal versus newborn and fetal versus adult.

${ }^{3} P<0.001$ fetal versus adult and newborn versus adult.
}

Comparisons were made for left and right ventricular tissues obtained from the same heart using the Student $t$ test for paired data. For other comparisons, the Student $t$ test for unpaired data was used. Results are expressed as the mean \pm 1 S.E.

\section{RESULTS}

\section{PROPERTIES OF THE DEVELOPING HEART}

As the heart develops, myocytes cease dividing and concomitantly become more differentiated $(5,6,16)$. This process is not confined to fetal development but continues during neonatal maturation. Per unit cardiac mass, protein, and dry weight contents increase while DNA content decreases. In Table 1, protein, dry weight, and DNA contents per unit ventricular mass for lamb fetuses (113 to 140 days gestation; term, 145 days) and for neonates to 21 days postpartum are compared with values characterizing adult ventricular tissue. These results show that fetal myocardium had lower protein and dry weight contents than neonatal and adult hearts. Decreases in DNA content, and presumably the rate of myocyte proliferation, occurred throughout the 7-wk period studied. The changes were gradual; DNA content was $5.1 \pm 0.01 \mu \mathrm{g} / \mathrm{mg}$ left ventricular tissue $(n=2)$ for the 115 to 117-day-old fetal heart; $3.1 \pm 0.02(n=3)$ for the 135- to 140-dayold fetal heart; $3.4 \pm 0.1(n=15)$ for 1- to 7-day-old neonates; and $2.8 \pm 0.1(n=5)$ for the 8- to 21-day-old neonate. Adult values $(\sim 1.4 \mu \mathrm{g} / \mathrm{mg})(n=9)$ were significantly lower. These results suggest that myocyte size increased about 2 -fold in the 7 -wk period studied and doubled again between 3 wk postpartum and full maturation. Electron microscopic studies (37) suggest that the increase in myocyte size is due to an increased accumulation of myofibrils.

\section{MATURATION OF THE CONTRACTILE APPARATUS}

In an attempt to identify whether the properties of the contractile apparatus are the same in late fetal, neonatal, and adult hearts, myosin, the major myofibrillar protein, was isolated from left and right ventricular tissues. Analysis of these preparations on sodium dodecyl sulfate-polyacrylamide gel electrophoresis suggests that all preparations were of comparable purity. $\mathrm{Ca}^{++}$-activated myosin ATPase activity was slightly, but significantly $(P<0.025)$, lower for myosin isolated from the hearts of 113- to 140-day-old fetal lambs than were values obtained for the adult. The activity of myosin prepared from the youngest fetal lambs was not different from myosin ATPase activity of 133- to 140-day-old fetal hearts $(1.03 \pm 0.10, n=3$ versus $1.17 \pm 0.07, n=9)$. The ATPase activity of myosin isolated from newborns on the first day of life was similar to that for fetal hearts. The specific activities of myosin isolated from 2- to 7- and 11- to 14-day-old neonatal hearts were
Table 2. $\mathrm{CA}^{++}$-activated myosin ATPase activities of fetal, neonatal, and adult sheep hearts

\begin{tabular}{|c|c|c|}
\hline \multirow[b]{2}{*}{ Age groups } & \multicolumn{2}{|c|}{ ATPase activity $\left(\mu \text { moles } \mathrm{P}_{\mathrm{i}} / \mathrm{g} \text { protein } / \mathrm{sec}\right)^{1}$} \\
\hline & Left ventricle & Right ventricle \\
\hline $113-140$ days gestation ${ }^{2}$ & $1.13 \pm 0.06^{3}(12)$ & $1.30 \pm 0.39$ \\
\hline Birth to 1 day & $0.96 \pm 0.05$ & $1.16 \pm 0.05(2)$ \\
\hline 2-14 days postpartum & $1.30 \pm 0.09(10)$ & $1.42 \pm 0.11(9)$ \\
\hline Adult $^{2}$ & $1.36 \pm 0.07$ & $1.36 \pm 0.10$ \\
\hline
\end{tabular}

${ }^{1} P<0.001$ left versus right ventricles for hearts from animals 113 days gestation to 14 days postpartum.

${ }^{2} P<0.025$ fetal versus adult.

${ }^{3}$ Mean \pm S.E.

not different $(1.27 \pm 0.13, n=6$ versus $1.34 \pm 0.09, n=4)$. These latter values were similar to those for the adult $(1.36 \pm 0.07)$. These results show that the intrinsic specific activity of myosin increases $(1.03 \pm 0.10$ versus $1.34 \pm 0.09)$ as the myocyte matures and that myocytes begin to accumulate adult-like myosin by the end of the period of gestation.

A paired analysis of the specific activities of myosin isolated from the left and right ventricle of two fetal and eleven neonatal hearts suggests that the right ventricle had slightly higher (approximately $14 \%)$ myosin ATPase activity $(P<0.005)$. This finding is consistent with the increased physiologic load on the right ventricle during fetal development. The difference in left and right ventricular myosin ATPase activity persists during early neonatal development as the mass of the right ventricle relative to the whole heart decreases. No differences between the ventricles were found for the adult (Table 2).

\section{MATURATION OF ATP-PRODUCING ENZYME SYSTEMS}

ATP utilized by the contractile apparatus (specifically by myo$\sin$ ) is regenerated by oxidative phosphorylation, glycolysis, and the transfer of high-energy phosphate from creatine phosphate to ADP via the Lohmann reaction (creatine phosphate + MgADP $\rightleftarrows$ creatine + MgATP). To assess (albeit incompletely) the capacity of fetal, neonatal, and adult hearts to maintain normal ATP levels, the activities of several enzymes known to participate in each of these three pathways were measured for tissue from each ventricle: mitochondrial creatine kinase, $\mathrm{MM}$ creatine kinase, and lactate dehydrogenase.

Total creatine kinase activity per unit ventricular mass (i.e., tissue concentration) and the tissue concentrations of each of the four creatine kinase isozymes (BB, MB, MM, and mitochondrial) were determined for left and right ventricular tissue for all age groups. Figure 1 illustrates the values obtained for total creatine kinase activity (IU/mg ventricular weight) for hearts from 113- 


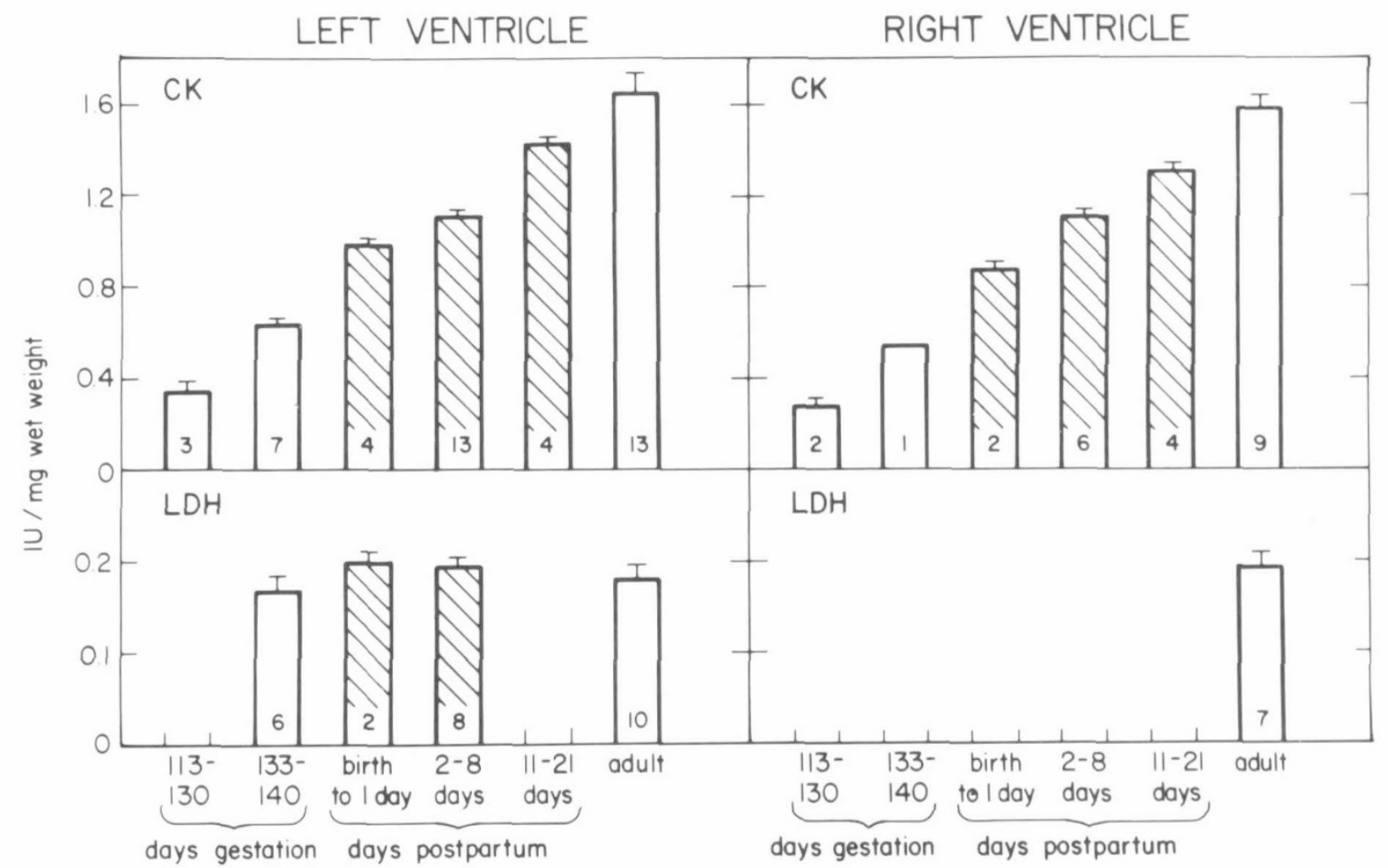

Fig. 1. Creatine kinase ( $C K$, top panels) and lactate dehydrogenase ( $L D H$, bottom panels) activities for left and right ventricular tissue of hearts from fetal, newborn, neonatal, and adult sheep. Hatched bars show values from neonatal myocardium. Activity is expressed as IU/mg wet weight. The numbers in the bars refer to number of animals studied, and values are given as mean $\pm \mathrm{S}$.E. Assays were carried out as described under "Materials and Methods."

day-old fetuses to 21-day-old neonates and the adult. Throughout the 7-wk period of development studied, the tissue concentration of creatine kinase activity progressively increased relative to total cardiac mass. This pattern is obtained whether tissue concentration was expressed as IU/unit wet weight, dry weight, or total cardiac protein (not shown). No differences were found between left and right ventricular tissues at any age.

Analysis of the distribution of creatine kinase isozymes (see Fig. 2 for a sample electrophoretogram) showed that fetal heart (115 to 140 days gestation) contained no $\mathrm{BB}, \sim 2 \pm 1 \% \mathrm{MB}, 93 \pm 1 \%$ $\mathrm{MM}$, and $5 \pm 1 \%$ mitochondrial creatine kinase activity $(\mathrm{n}=6)$. The isozyme distribution for left ventricular tissue was the same for all hearts isolated from newborns through the adult; these hearts contained only trace amounts of $\mathrm{MB}, 86 \pm 1 \% \mathrm{MM}$, and 14 $\pm 1 \%$ mitochondrial creatine kinase $(n=30)$. No differences were found between left and right ventricular tissues. Thus, in terms of isozyme distribution, the newborn heart resembled the adult; however, in terms of the tissue concentration of the isozymes, hearts from young animals were not fully mature. An estimate of the tissue concentrations of each of these isozymes can be obtained by multiplying the percentage distribution by the total creatine kinase activity. Table 3 shows the results of this calculation for seven hearts representing the developmental period under study. During the 30 days between 115 days gestation and birth, the concentration of the mitochondrial isozyme increased about 10fold, whereas the increase for the MM isozyme was 4-fold. Thus, during this period of development, the tissue concentrations of these two creatine kinase isozymes increased relative to other cardiac proteins, but the mitochondrial isozyme accumulated faster than did the MM isozyme. During the first 2 to $3 \mathrm{wk}$ of postnatal development, the concentration of both $\mathrm{MM}$ and the mitochondrial isozyme increased relative to total cardiac protein and, on the average, they did so coordinately.

Developmental changes also occur in the tissue concentrations of the substrates for the creatine kinase reaction. Left ventricular concentrations of total creatine, i.e., free creatine + creatine phosphate, were $5.8 \pm 1.0 \mathrm{nmoles} / \mathrm{mg}$ wet weight $(n=3)$ for 115 - to

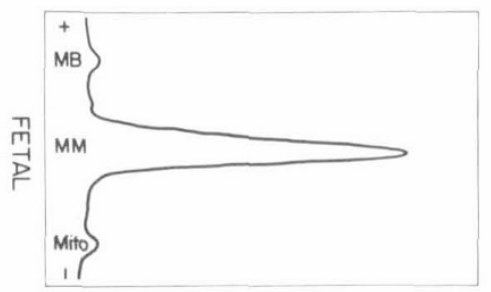

Fig. 2. Distribution of creatine kinase isozymes for fetal sheep heart using cellulose acetate strip electrophoresis. Details of the methods used are given under "Materials and Methods."

Table 3. Tissue concentrations of creatine kinase isozymes

\begin{tabular}{lrrrr}
\hline \multicolumn{1}{c}{ Age } & \multicolumn{4}{c}{$\begin{array}{c}\text { Creatine kinase activity } \\
(\mathrm{mIU} / \mathrm{mg} \text { wet wt })\end{array}$} \\
\cline { 2 - 5 } & Total & MB & MM & Mitochondrial \\
\hline 115 days gestation & 213 & $<10$ & 200 & $<10$ \\
135 days gestation & 580 & Trace & 550 & 30 \\
6 hrs after birth & 920 & Trace & 830 & 90 \\
7 days postpartum & 1120 & Trace & 950 & 170 \\
14 days postpartum & 1410 & Trace & 1170 & 240 \\
21 days postpartum & 1480 & Trace & 1230 & 250 \\
Adult & 1630 & Trace & 1360 & 270
\end{tabular}

140-day-old fetuses, $14.8 \pm 1.7(n=4)$ for newborns, $14.1 \pm 0.6$ $(n=15)$ for 2 - to 14-day-old neonates and $14.9 \pm 0.7(n=6)$ for adults. No differences were found between left and right ventricular myocardium at any age. These results indicate that a greater than 2 -fold increase in the total creatine pool (and presumably the creatine phosphate pool) occurred during the last month of fetal development, concurrent with the appearance and increased accumulation of the mitochondrial creatine kinase isozyme. After birth, the creatine concentration was constant, i.e., it increased 
coordinately with the increase in cardiac mass. In contrast to this increase in the creatine pool, little or no change occurred in the ATP pool. ATP concentrations (nmoles/mg wet weight), measured in rapidly frozen heart biopsies, as previously described (32), were $5.2 \pm 0.2(n=23)$ for fetal lamb heart, $6.0 \pm 0.3(n=14)$ for newborn heart, and $6.1 \pm 0.4(n=18)$ for adult heart (11).

In contrast to the maturational changes found in the creatine kinase system, no significant changes were observed for the tissue concentration of the glycolytic enzyme, lactate dehydrogenase, during the period of development studied (Fig. 1). The ratio of lactate dehydrogenase activities at high and low substrate (pyruvate) concentrations has been used as a measure of relative isozyme composition (3). Values of $\sim 0.8$ are characteristic of isozymes found in tissues relying primarily on anaerobic ATP production; ratios of 0.1 to 0.2 are characteristic of tissues undergoing aerobic metabolism. This ratio was the same for hearts of all animals studied: $0.15 \pm 0.01(n=6)$ for fetal lambs, $0.13 \pm 0.01$ $(n=12)$ for neonatal lambs, and $0.14 \pm 0.01(n=11)$ for adult sheep. No differences were found between left and right ventricular myocardium at any age.

\section{DISCUSSION}

Previous studies from our laboratory have shown that isometric force development and the extent and velocity of shortening at any load are lower in the developing lamb heart when compared to the adult sheep (10). We have speculated that ultrastructural differences in myofibrillar size and number with advancing age may account for some of these mechanical differences $(10,29)$, whereas others have suggested that an age-dependent maturation of excitation-contraction coupling might contribute to the differences noted in the intrinsic physiological properties of the developing heart (19). The current study examines the possibility that a maturation of energy metabolism may also contribute to the augmentation in force development and shortening characteristic of ventricular myocardium during the transition from fetal to postnatal to adult life.

Barany (2) and Drachman and Johnston (7) have shown that myosin ATPase activity correlates with speed of contraction in a variety of muscles. Thus, a reduction in the heart's mechanical performance may result from differences in the intrinsic enzymatic activities of actomyosin or myosin. Differences in the concentration of the contractile proteins in the myocyte may also be important.

In addition to changes in ATP utilizing processes, it is also possible that changes in high-energy phosphate-producing pathways play an important role in determining the capacity of heart muscle to shorten, generate, and maintain force. These pathways include ATP production by anaerobic pathways (glycolysis) and by aerobic pathways (oxidative phosphorylation in the mitochondria) and rephosphorylation of ADP by creatine phosphate via the creatine kinase reaction. The relative importance of these three pathways may be different in the maturing myocardium. For example, it has been shown in the mouse (4) and sheep (40) that glycolytic capacity is relatively greater in the fetus than in the adult. Changes in oxidative metabolism are reflected in the increased fractional area occupied by mitochondria in the myocyte $(3,27,30)$, by increased tissue concentrations of some mitochondrial enzymes $(22,45)$, and by studies of mitochondrial oxidative phosphorylation $(38,42,44)$. Finally, developmental changes in the concentration and distribution of creatine kinase isozymes and their substrates have been shown to occur in fetal and neonatal life in a variety of species (17).

The current studies were undertaken in view of the possible physiologic importance of maturation of the enzyme systems central to energy production and utilization.

\section{MYOFIBRILLAR PROTEINS}

The results reported show that the specific activity $\left(\mathrm{Ca}^{++}\right.$-activated) of cardiac myosin ATPase in lamb fetuses and newborns was approximately $20 \%$ less than adult values; from the second day of life to adulthood, no further increase was found. Both ventricles participate concordantly in these age-related changes. It should be emphasized that the observed changes in specific activity are not large and that attempts to show differences in myofibrillar ATPase activity between fetal, neonatal, and adult sheep hearts have been unsuccessful (10). Even small differences in intrinsic specific activity, however, may contribute to differences in the structure, assembly, and function of the protein. Developmentally related increases in myosin ATPase activity have also been reported for neonatal rat heart (1) and in actomyosin ATPase activity for fetal calf heart (26). In view of the recent reports (12, $31,39)$ identifying myosin isozymes characteristic of fetal and adult skeletal and cardiac muscles in the rabbit, one may speculate that alterations in structure and function (i.e., ATPase activity) in the developing sheep heart may be due to the presence of different myosin isozymes.

In the fetus and neonate (but not the adult), myosin ATPase activity was slightly higher in the right than the left ventricle. The right ventricle is the dominant pumping chamber in utero and, after birth, increases in size and wall thickness more slowly than the left ventricle; the ratios of weight of the right ventricle to whole heart and to body weight actually decrease after birth (33). It may be that the slightly higher myosin ATPase activity in the developing right ventricle is related to its augmented workload in utero when compared to the left ventricle.

Electron microscopic studies from our laboratory of fetal (90 to 146 days gestation), neonatal ( 2 to 36 days postpartum), and adult sheep hearts have shown that there is a progressive increase in the ratio of contractile to noncontractile mass during this time of development $(10,37)$. Sarcomere length increases from $1.5 \mu$ in fetal heart to 1.8 to $2.0 \mu$ in the neonate, and fiber diameter increases from 0.8 to $1.1 \mu$ between 90 days gestation and term. Thus, taking all this evidence into account, there appear to be agedependent alterations in the cellular concentration, assembly, and intrinsic activity of myosin.

\section{ATP-PRODUCING ENZYMES}

The concentration of ATP in ventricular tissue has been found to be essentially constant over the age range studied, but the metabolic pathways by which synthesis is balanced by utilization differ in the fetus, newborn, and adult. Myocardial ATP production in heart occurs primarily by oxidative phosphorylation in the mitochondria. In rodent myocardium, maturation of the inner mitochondrial membrane, and presumably oxidative metabolism, occurs concomitantly with accumulation of the mitochondrial creatine kinase isozyme and with increased tissue creatine levels (17). Using first appearance and rapid accumulation of the mitochondrial creatine kinase isozyme as an index of mitochondrial maturation in the lamb heart, the results reported here suggest that biochemical maturation of the mitochondria occurs coordinately with structural maturation. Scanning electron microscopic studies have revealed profound differences in the shape, size, and distribution of mitochondria in the fetal and neonatal lamb when compared to the adult sheep (37). Fetal hearts contain long, branching mitochondria. As the heart matures, many small, budding mitochondria can be found. The neonatal heart contains larger mitochondria aligned between the myofibrils, characteristic of the adult heart.

According to the theory advocated by Bessman and Fonyo (4), Saks et al. (36), and Jacobus and Lehninger (18), the location of the mitochondrial creatine kinase is such that it functions to transfer high-energy phosphate from ATP formed by oxidative phosphorylation to creatine and as much as $90 \%$ of the highenergy phosphate produced by oxidative phosphorylation could be transported to the myofibrils as creatine phosphate, not ATP. If creatine phosphate is the transport molecule for high-energy phosphate in the adult myocardium, accumulation and assembly of the mitochondrial creatine kinase isozyme could play an important role in the maturation of cardiac energy metabolism. Our 
studies suggest that this maturation occurs around birth in the lamb. Between 115 days gestation and birth, the distribution of the mitochondrial creatine kinase isozyme (i.e., percentage of total activity) increased from $\sim 2$ to $\sim 14 \%$ (i.e., from barely detectable to adult levels). Moreover, the tissue concentration of this protein increased over 25-fold between 115 days gestation and 2 wk postpartum. The tissue concentration of one set of substrates for the creatine kinase reaction, i.e. the creatine pool, also increased during the last month of gestation. It is tempting to speculate that the increase in the creatine pool (from $\sim 6$ to $\sim 15$, or a difference of 9 nmoles/mg cardiac mass) represents the pool which is phosphorylated by the mitochondrial creatine kinase isozyme.

Thus, there is both biochemical and ultrastructural evidence suggesting that mitochondrial structure and function is mature in many respects even in the newborn lamb heart. Maturation may not be fully complete, however, because previous reports from this laboratory have shown that oxygen consumption in isolated, uncoupled mitochondrial from the newborn is different from that in the adult (42).

The MM-creatine kinase isozyme, localized in part in the myofibril and in the cytoplasm (4I), is the dominant cardiac isozyme $(>85 \%)$ even in the youngest heart studied. Thus far, in all species studied except the frog and chicken (8), the B polypeptide chain is dominant (albeit in low concentrations) only in embryonic heart and terminal differentiation is characterized by first appearance and rapid accumulation of the $\mathrm{M}$-polypeptide chain. During the 7 wk of fetal and neonatal development analyzed in the present study, the MM-isozyme accumulated faster than average cardiac proteins (6-fold increase between 115 days gestation and 3 wk neonatal life). Thus, in contrast to differentiation in the rodent which occurs postnatally, this enzyme system matures in the lamb well before birth.

Although large, age-related changes were seen in the cellular accumulation of mitochondrial and MM-creatine kinase isozymes, no developmental augmentation was observed in either the tissue content nor isozyme composition of the glycolytic enzyme, lactate dehydrogenase. Thus, we suggest that age-related alterations in lactate dehydrogenase occurred earlier than 115 days gestational age in the lamb.

The current findings, combined with those of others, indicate that the structure and function of the two major myocardial organelles, the myofibrils and mitochondria, undergo progressive maturation during late fetal development. Changes in the isozyme composition of the enzyme systems studied herein are essentially complete near birth. Postnatal cardiac development is characterized by accumulating more of the cell-specific proteins, namely myosin, MM, and mitochondrial creatine kinase isozymes. Although measurements were not made of myosin content in the current studies, the tissue concentrations of creatine kinase isozymes reached adult levels by 14 to 21 days postpartum. Thereafter, creatine kinase accumulates in proportion to the increase in cardiac mass.

The results of the present investigation support the hypothesis that the composition and structure of myofibrils and mitochondria, energy-utilizing and -producing organelles, change during late fetal development and early neonatal life of the sheep. These findings contribute to our understanding of how energy metabolism may participate in the regulation of the mechanical performance of the heart.

\section{REFERENCES AND NOTES}

1. Baldwin, K. M., Cooke, D. A., and Cheadle, W. G.: Enzyme alterations in neonatal heart muscle during development. J. Mol. Cell. Cardiol., 96: 651 (1977).

2. Barany, M.: ATPase activity of myosin correlated with speed of muscle shortening. J. Gen. Physiol., 50: 197 (1967).

3. Bernstein, L. H., and Everse, J.: Determination of isoenzymes of lactic dehydrogenase. Methods Enzymol., 41: 47 (1975).

4. Bessman, S. P., and Fonyo, A.: The possible role of the mitochondrial bound creatine kinase in regulation of mitochondrial respiration. Biochem. Biophys. Res. Commun., 22: 597 (1966).
5. Claycomb, W. C.: Biochemical aspects of cardiac muscle differentiation. Biochem. J.. 171: 289 (1978)

6. Claycomb. W. C.: DNA synthesis and DNA enzymes in terminally differentiating cardiac muscle cells. Exp. Cell. Res., 118: 111 (1979).

7. Drachman. D. B., and Johnston. D. M.: Development of a mammalian fast muscle: dynamic and biochemical properties correlated. J. Physiol. (Lond.), 234: 29 (1973).

8. Eppenberger. M. E.. Eppenberger, H. M.. and Kaplan, N. O.: Evolution of creatine kinase. Nature (Lond.). 214: 239 (1967).

9. Fiske, C. H., and Subbarow, Y.: Estimation of inorganic phosphate. J. Biol. Chem.. 66: 375 (1925).

10. Friedman, W. F.: The intrinsic physiologic properties of the developing heart. Progr. Cardiovasc. Dis., 15: 87 (1972).

11. Friedman. W. F.: unpublished results.

12. Gauthier, G. F., Lowry, S., and Hobbs, A. W.: Fast and slow myosin in developing muscle fibres. Nature (Lond.), 274: 25 (1978).

13. Hall. N. F., and DeLuca, M.: Electrophoretic separation and quantitation of creatine kinase isozymes. Anal. Biochem., 76: 561 (1976).

14. Hinegardner, R. T.: An improved fluorometric assay for DNA. Anal. Biochem., 39: 197 (1971).

15. Ingwall, J. S.: Creatine and the control of muscle-specific protein synthesis in cardiac and skeletal muscle. Circ. Res., 38: 115 (1976).

16. Ingwall, J. S.: Metabolism of proteins and nucleic acids during muscle differentiation. In: K. Wildenthal: Degradative processes in Cardiac and Skeletal Muscles. pp. 131-159 (Elsevier-Holland, Amsterdam, 1980).

17. Ingwall, J. S., Kramer, M. F., and Friedman, W. F.: Developmental changes in heart creatine kinase. In: W. E. Jacobus, J. S. Ingwall: Heart Creatine Kinase. pp. 9-17 (The Williams \& Wilkins Co., Baltimore, 1980).

18. Jacobus, W. E., and Lehninger, A. L.: Creatine kinase of rat heart mitochondria. J. Biol. Chem., 248: 4803 (1973).

19. Jarmakani, J. M.. Nagatomo, T., and Langer, G. A.: The effect of calcium and high energy phosphate compounds on myocardial contracture in the newborn and adult rabbit. J. Mol. Cell. Cardiol., 10: 1017 (1978).

20. Kammermeier, H.: Microassay of free and total creatine from tissue extracts by combination of chromatographic and fluorometric methods. Anal. Biochem., 56: 341 (1973).

21. Katz, A. M.: Contractile proteins. Methods Pharmacol., J: 410 (1971).

22. Kinnula, V. L., and Hassinen, I.: Effect of hypoxia on mitochondrial mass and cytochrome concentrations in rat heart and liver during postnatal development. Acta Physiol. Scand., 99: 462 (1977).

23. Kirkpatrick, S. E., Covell, J. W., and Friedman, W. F.: A new technique for the continuous assessment of fetal and neonatal cardiac performance. Am. J. Obstet. Gynecol., 116: 963 (1973).

24. Kirkpatrick, S. E., Naliboff, J., Pitlick, P. T., and Friedman, W. F.: The influence of post stimulation potentiation and heart rate on the fetal lamb heart. Am. J. Physiol., 229: 318 (1975).

25. Kirkpatrick. S. E., Pitlick, P. T., Naliboff, J., and Friedman, W. F.: The importance of the Frank-Starling relationship as a determinant of fetal cardiac output. Am. J. Physiol., 231: 495 (1976)

26. Lebedeva, N. A., Solovey, A. L., and Efimaya, L. F.: Age peculiarities of actomyosin enzymic properties in embryogenesis. Ukr. Biokhim. Zh., 50: 419 (1978).

27. Legato, M. J.: Ultrastructural changes during normal growth in the dog and rat ventricular myofibril. In: M. Lieberman, T. Sarco: Developmental and Physiological Correlates of Cardiac Muscle. (Raven Press, New York, 1975).

28. Lowry, O. H., Rosebrough, N. J., Farr, A. L., and Randall, R. J.: Protein measurement with the Folin phenol reagent. J. Biol. Chem., 193: 265 (1951).

29. McPherson, R. A., Kramer, M. F., Covell, J. W., and Friedman, W. F.: A comparison of the active stiffness of fetal and adult cardiac muscle. Pediatr. Res., 10: 660 (1976).

30. Page, E., Earley, J., and Power, B.: Normal growth of ultrastructures in rat left ventricular myocardial cells. Circ. Res., 35 (Suppl. II): 12 (1974).

31. Pelloni-Muller, G., Ermini, M., and Jenny, E.: Changes in myosin light and heavy chain stoichiometry during development of rabbit fast, slow and cardiac muscle. FEBS Lett., 70: 113 (1976).

32. Pool, P. E., Chandler, B. M., Sonnenblick, E. H., and Braunwald, E.: Integrity of energy stores in cat papillary muscle. Circ. Res., 22: 213 (1968).

33. Romero, T., Covell, J., and Friedman, W. F.: A comparison of the pressurevolume relations of the fetal, newborn, and adult heart. Am. J. Physiol., 222: 1285 (1972).

34. Romero, T. E., and Friedman, W. F.: Limited left ventricular response to volume overload in the neonatal period: a comparative study with the adult animal. Pediatr. Res., 13: 910 (1979).

35. Rosalki, S. B.: An improved procedure for serum creatine phosphokinase determination. J. Lab. Clin. Med., 69: 696 (1967).

36. Saks, V. A., Chernousova, G. B., Gukovsky, D. E., Smirnov, V. N., and Chazov, E. I.: Studies of energy transport in heart cells: mitochondrial isoenzymes of creatine phosphokinase. Eur. J. Biochem., 57: 273 (1975).

37. Sheldon, C. A., Friedman, W. F., and Sybers, H. D.: Scanning electron microscopy of fetal and neonatal lamb cardiac cell. J. Mol. Cell. Cardiol., 8: 853 (1976).

38. Sordahl, L. A., Crow, C. A., Kraft, G. H., and Schwartz, A.: Some ultrastructural and biochemical aspects of heart mitochondria associated with development. J. Mol. Cell. Cardiol., 4: 1 (1972).

39. Sreter, F. A., Balint, M., and Gergely, J.: Structural and functional changes of myosin during development. Dev. Biol., 46: 317 (1975). 
40. Su, J. Y., and Friedman, W. F.: Comparison of the responses of fetal and adult cardiac muscle to hypoxia. Am. J. Physiol., 224: 1249 (1973).

41. Turner, D. C., Wallimann, T., and Eppenberger, H. M.: A protein that binds specifically to the M-line of skeletal muscle is identified as the muscle form of creatine kinase. Proc. Natl. Acad. Sci. U. S. A.. 70: 702 (1973).

42. Wells, R. J., Friedman, W. F., and Sobel, B. E.: Increased oxidative metabolism in the fetal and newborn lamb heart. Am. J. Physiol., 222: 1488 (1972).

43. Wildenthal, K.: Fetal maturation of cardiac metabolism. In: R. S. Comline et al.: Foetal and Neonatal Physiology. pp. 181-185 (Cambridge University Press, Cambridge, 1973).

44. Wittels, B., and Bressler, R.: Lipid metabolism in the newborn heart. J. Clin.
Invest., 44: 1639 (1965).

45. Zeit-Har, S. A., and Drahota, Z.: The development of mitochondrial oxidative enzymes in rat heart muscle. Physiol. Bohemoslov., 24: 289 (1975).

46. Requests for reprints should be addressed to: Joanne S. Ingwall, Ph.D., Brigham and Women's Hospital, 75 Francis St., Boston, MA 02115 (USA).

47. This research was supported by NIH grant HL 25476 to Dr. Friedman and by NIH grants HL 20552 and HL 22290 and grants from the San Diego and Massachusetts Affiliates of the American Heart Association to Dr. Ingwall. Dr. Ingwall is an Established Investigator of the American Heart Association.

48. Received for publication August 14, 1980.

49. Accepted for publication January 9, 1981

Copyright (C) 198 I International Pediatric Research Foundation, Inc. $0031-3998 / 81 / 1508-1128 \$ 02.00 / 0$ 